OAK RIDGE
$\frac{\text { NATIONAL LABORATORY }}{\text { MANAGED BY UT-BATTELLE }}$
FOR THE DEPARTMENT OF ENERGY

ORNL/LTR-2015/407

\title{
RILEM TC ISR Summer 2015 Activity Report
}

August 2015

Prepared by

Yann Le Pape

Oak Ridge National Laboratory

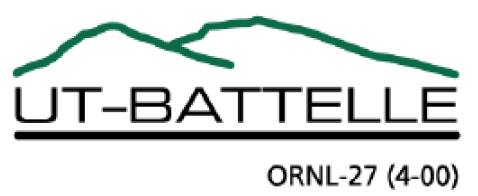


This report was prepared as an account of work sponsored by an agency of the United States Government. Neither the United States Government nor any agency thereof, nor any of their employees, makes any warranty, express or implied, or assumes any legal liability or responsibility for the accuracy, completeness, or usefulness of any information, apparatus, product, or process disclosed, or represents that its use would not infringe privately owned rights. Reference herein to any specific commercial product, process, or service by trade name, trademark, manufacturer, or otherwise, does not necessarily constitute or imply its endorsement, recommendation, or favoring by the United States Government or any agency thereof. The views and opinions of authors expressed herein do not necessarily state or reflect those of the United States Government or any agency thereof. 


\section{Subject Matter}

With aging infrastructures, instances of Alkali Silica Reaction (ASR) and Delayed Ettringite Formation (DEF), broadly covered under the term Internal Swelling Reaction (ISR), are increasingly being detected. They have been observed in bridges, dams, and most recently in nuclear power plants. Concrete swelling may result in bridge partial failure, dams with structural cracks and misaligned turbine shafts, and locked slice gates. For nuclear reactors micro-cracks may cause increased gas permeability which will jeopardize the containment integrity and may decrease the residual structural resistance under accidental loading. This TC, which limits its activity to structures with known expansive concrete, seeks to address two complementary but fundamental questions: a) What is the kinetics of the reaction and b) How would it affect the integrity of the structure (serviceability and strength) and thus establish a science based prognostic to the structure owner.

\section{Active Members}

Mohammed Alnaggar (Rensselaer Polytechnic Institute), Francesco Amberg (Lombardi Consulting), Carmen Andrade (IETcc - CSIC), Fateh Boussaha (Hydro-Québec), João Custódio (Laboratório Nacional de Engenharia Civil - LNEC), Rui Miguel Ferreira (VTT Technical Research Centre of Finland), John Fraczek (Wiss, Janney, Elstner Associates, Inc.), Eric R. Giannini (University of Alabama), Laurence Jacobs (Georgia Technology Institute), Anca-Cristina Jurcut (University of Toronto), Tetsuya Katayama (Taiheiyo Consultant Co., Ltd), Yuichiro Kawabata (Port and Airport Research Institute), Selmo C. Kuperman (DESEK), Yann Le Pape (Oak Ridge National Laboratory), Andreas Leemann (Eidgenössische Materialprüfungs- und Forschungsanstalt - EMPA), Renaud-Pierre Martin (Institut Français des Sciences et Technologies des Transports, de l'Aménagement et des Réseaux - IFSTTAR) Esperanza Menendez Mendez (IETcc - CSIC), Christine Merz (ungricht merz gmbh), Stéphane Multon (Université de Toulouse), Hiroaki Noguchi (Tokyo Electric Power Service Company), Nebojsa Orbovic (Canadian Nuclear Safety Commission), Daman K. Panesar (University of Toronto), Jianmin Qu (NorthWestern), Patrice Rivard (Université de Sherbrooke), Leandro Sanchez (University of Ottawa), Gaurav Sant (University of California, Los Angeles), Victor E. Saouma (University of Colorado), Erik Schlangen (TU Delft), Alain Sellier (Université de Toulouse), Henrik Erndahl Sørensen (Danish Technological Institute), Yuya Takahashi (University of Tokyo), Sofie Tremblay (LVM), Kazuo Yamada (National Institute for Environmental Studies).

\section{Google Drive}

Background materials, surveys, presentations are uploaded on the Google Drive RILEM-ASR-Prognosis. Contact V. Saouma or Y. Le Pape if you still need to request an access or if you have problems connecting to the drive.

\section{June 262015 Annual Meeting}

Participants $\quad v$ : videoconference, $\uparrow$ : invited guest.

Francesco Amberg ${ }^{v}$ (Lombardi Consulting, Switzerland), Ricardo Barbosa, (Danmarks Tekniske Universitet, Denmark), Juão Custódio, (Laboratório Nacional de Engenharia Civil (LNEC), Portugal), Cyrille 
Dunant $^{\dagger}$, (Ecole Polytechnique Fédérale de Lausanne (EPFL), Switzerland), Manouchehr Hassanzadeh ${ }^{\dagger},{ }^{1}$, (Vattenfall AB, Sweden), Adrien Hilaire ${ }^{\dagger}$, (Ecole Polytechnique Fédérale de Lausanne (EPFL), Switzerland), Lawrence Jacobs ${ }^{v}$, (Georgia Institute of Technology, USA), Tetsuya Katayama ${ }^{\dagger}$, (Taihaiyo Consultant Co. Ltd, Japan), Yushihiro Kawabata, (Port and Airport Research Institute, Japan), Andreas Leemann, (Eidgenössische Materialprüfungs- und Forschungsanstalt (EMPA), Switzerland), Yann Le Pape, (Oak Ridge National Laboratory, USA), Renaud-Pierre Martin, (Institut Français des Sciences et Technologies des Transports, de l'Aménagement et des Réseaux (IFSTTAR), France), Esperenza Menéndez, (Instituto Eduardo Torroja, Spain), Stéphane Multon, (Université de Toulouse, France), Georges Nahas ${ }^{\dagger}$, (Institut de Radioprotection et de Sûreté Nucléaire, France), Patrice Rivard ${ }^{v}$, (Université de Sherbrooke, Canada), Leonardo Sanchez, (McGill University, Canada), Victor Saouma, (University of Colorado, USA), Alain Sellier, (Université de Toulouse, France), Yuya Takahashi ${ }^{\dagger},{ }^{2}$, (University of Tokyo, Japan), Kazuo Yamada, (National Institute for Environmental Studies (NIES), Japan)

Venue: The meeting was hosted by R.-P. Martin at the IFSTTAR facilities in Marne-la-Vallée, France. The TC ISR gratefully thanks R.-P. Martin and IFSTTAR for arranging this meeting and providing lunchs and refreshments to the participants.

\subsubsection{Agenda}

1. 9:30 Welcome

2. 9:45 Introduction

3. 10:00 State of the Art - F. Amberg* (Lombardi) and V. Gocevski (Hydro Quebec).

4. 11:00 WG-1 Materials Testing - M. Hassanzadeh (Vattenfall) and V. Saouma (U. of Colorado)

5. 12:00 Lunch

6. 13:30 WG-2 Numerical Modeling - A. Sellier (U. of Toulouse)

7. 14:30 WG-4 Large scale testing - Y. Le Pape (Oak Ridge NL) and N. Orbovic (Canadian Nuclear Safety Commission).

8. 15:30 WG-3 Non Destructive Testing and Monitoring - L. Jacobs* (Georgia Tech) and P. Rivard* (U. of Sherbrooke).

9. 16:30 Discussion and Action Items

10. 17:00 Adjourn

names indicate the main speaker's names.

*: remote video conference connexion.

Details of the discussions and accomplishments are provided in the following sections.

\footnotetext{
${ }^{1}$ Jan Trägårgh from Swedish Cement and Concrete Research Institute is a RILEM member and worked cooperatively with M. Hassanzadeh

${ }^{2}$ Joined RILEM since then.
} 


\section{State of the Art and Research Needs}

V. Saouma mailed V. Gosevski (Hydro Quebec) and F. Amberg (Lombardi) the following request: "As part of our RILEM activities, I would like to ask two "stakeholders" to identify the actual/real/practical needs of their respective communities in terms of our committee activities."

V. Gosevski is currently developing a report entitled "Impacts of alkali-silica reaction (ASR) on Nuclear Power Plants; Problems and Research Needs". Note that parts of this report were published in the report submitted to the OECD project ASCET under the title "Pathologies/Degradation Mechanisms Experienced by Hydro-Quebec during the Evaluation of Gentilly-2 nuclear power plant (NPP)". This preliminary draft is currently circulating. V. Gosevski's report contains invaluable information on the effects, the simulations and the in-situ condition assessment of alkali-aggregate reaction (AAR) on the containment building and the enclosed substructures, the spent fuel storage pool and the turbo-generator foundation. Also, it should be noted in the interest of the WG4 on large-scale testing that this report provide information on a ASR test conducted under biaxial loading at the University of Sherbrooke.

F. Amberg is currently developing a report on "ASR in hydraulic structures" that includes the questions of the Identification of ASR on site, the analysis of some case historie, the factors affecting the ASR development, the potential failure modes, some remedial workand the assessment of actual current stress state. This report also aims at providing suggestions in terms of research needs for the TC ISR.

V. Gosevski and F. Amberg's reports are expected to be merged into one unique state of the art report "Impacts of ASR on Hydraulic Structures and Nuclear Power Plants; Problems and Research Needs".

\section{WG1. Residual Expansion}

M. Hassanzadeh (Ed.), J. Trägårdh, R.-P. Martin, S. Multon, A. Sellier, A. Leemann, C. Mertz and V. Saouma have compiled a draft report on four laboratory test procedures for the Estimation of the Residual Expansion of Concrete in Structures Affected by Alkali Silica Reactions. The following methods are included:

1. LPC N ${ }^{\circ}$ C44 (POC: R.-P. Martin, B. Godart and F. Toulemonde)

2. Swiss method (POC: C. Merz and A. Leemann)

3. Toulouse method (POC: S. Multon and A. Sellier)

4. Quebec method (Laval University) / U.S. Department of Transportation (DOT) (POC. M. Bérubé)

The methods cover the laboratory determination of the swelling potential and the residual free expansion of concrete extracted from structures affected by alkali silica reactions. The test methods do not encompass the assessment of the reaction advancement in the structure. All four methods are compiled separately as step-by-step procedures in this report.

At the suggestion of R.-P. Martin, J. Wood (Structural Studies \& Design Ltd) also agreed to send his method for incorporation in the final report.

C. Dunant will also provide the EPFL procedure.

Contributions to this task are due October 1st 2015 before circulating the draft among the TC members.

It is suggested that the next step will be a round-robin test of the different methods on the same concrete formulation. Severals options in terms of formulation and specimens providers are under discussion including one from V. Saouma in relation with his on-going work sponsored by the Nuclear Regulatory 
Commission (NRC) and one from Y. Le Pape in relation with the 'panel' testing at the University of Tennessee, Knoxville (UTK).

\section{WG2. Numerical Modeling}

\section{Survey}

A. Sellier has developed and submitted to the RILEM members an internet survey on the modeling strategies currently employed by the TC members. All five replies were received from the Academia (University of Colorado, University of Toulouse, UPC- Barcelona, University of Tokyo and, University of Toronto). C. Dunant told his intend to provide a contribution from Ecole Polytechnique Fédérale de Lausanne. All are also code developers. Hence, the results of this survey could be more relevant of the on-going trends in terms of advanced modeling tools than a picture of the state of the art of modeling used by industry practitioners although this statement may vary from country to country.

It appears that:

1. The use of empirical sigmoidal expansion curve is gradually abandoned to the benefit of differential formulation that typically accounts for the temperature, but not so much on the relative humidity.

2. The varied modeling approaches include meso-scale and macro-scale approaches.

3. Concrete constitutive (mechanical) models always account for damage although in various ways: damage, plasticity, viscoplasticity or smeared rotating crack.

4. All models can be considered as rather sophisticated in terms of non linearities accounted for: tensile and compressive strengths, fracture energy in tension, possibility to close previously opened cracks in tension, nonlinear hardening in compression. Most models also account for nonelastic strains in tension, compression or shear.

5. Creep and shrinkage are also included in most models.

6. The ASR isotropic equivalent-thermal expansion has been fully abandoned. Anisotropic swelling function of the stress state is accounted by all models.

7. Tensile strength and Young modulus are affected by ASR in all models.

8. It is noted that, to one exception, most models do not consider potential effects of ASR on the steelconcrete interface.

9. The characterization of the chemical model parameters is performed by varied approaches: inverse analysis of the structural displacement monitoring, or, laboratory results, primarily on the aggregate properties but never on residual expansion testing, or both.

10. In terms of reliability, most models have not been confronted to experimental results to assess the effects of temperature and relative humidity.

11. While the influence of principal stresses (i.e., uniaxial, biaxial or triaxial conditions) on the expansion amplitude has been assessed with most models, the effects of shear condition appears very limited. 
12. While most models have been employed to model laboratory reinforced concrete (RC) beams, a lack of confrontation against large RC members is noted.

Although, it was not initially anticipated to submit a benchmark on meso-scale modeling, the survey reviews show the need to modify this position.

A. Sellier noted that "As it is impossible to have a reliable fitting with only laboratory test or only structural analysis, most of these models are usable only to extrapolate current behavior in the foreseeable future. Progress in WG 1 could extend their prediction capability to a more distant future."

Most model developers are willing to provide a brief description of their models (layout provided by A. Sellier) and are also willing to participate to a numerical benchmark. Specification are provided in A. Sellier's presentation (See Google Drive folder: WG-2-Numerical-Modeling/Update june 15 AS.

\section{Benchmark Preparation}

Tailored on the results of the survey, Pr. Sellier has developed a proposal for a benchmark that includes materials (7 tests) and structural simulations.

The materials simulations aim at targeting the following questions: temperature and moisture content effects, anisotropic swelling under anisotropic stress state, creep and nonlinear behavior of concrete. It is requested that each participant models the seven proposed tests to obtain a comprehensive pictures of the models capabilities. The materials simulation benchmark is open to macro-scale and meso-scale models.

The five structural simulation tests being more time consuming, it is suggested that each participants pick a test.

Practical information about the benchmark

1. A pdf document describing the tests to perform will be send to interested people

2. A pre-formatted file will be send to upload the participants results.

In addition, each team/participants will supply a word format file including the 5 pages describing their model, and complements about studied tests

To register to the benchmark and obtain the files (pdf and excel) send an email to sellier@insa-toulouse . fr and cc Saouma@Colorado.EDU

\section{WG3. Monitoring and Nondestructive Evaluation}

L. Jacobs, P. Rivard and E. Giannini are preparing a state-of-the art report on monitoring varied parameters relevant for ASR-affected structures: humidity/moisture content, alkali content, temperature, displacement and deformation, internal stresses, and, damage and cracking. For each studied parameters, the relevancy toward ASR and the measurement techniques (in laboratory or in situ) are discussed. Additionally, case studies from the open literature are reported. The draft report is expected to be ready for circulation among the TC members in September.

\section{WG4. Large-Scale Testing}

The term large-scale testing is somewhat ambiguous but refers, in the context of this TC, to structural members, i.e., beam, wall, panel including reinforcement. 


\section{Past programs}

1. Laboratoire Central des Ponts et Chaussées (LCPC) : structural behavior of RC beams subject to ASR and moisture content gradient.

2. TX DOT/University of Texas at Austin : shear resistance (4-point bending test) of ASR-affected beam with shear reinforcement (bridge girder).

3. Hydro-Quebec/Université de Sherbrooke (See WG1 report provided by V. Gosevski)

\section{On-going programs:}

1. Canadian Nuclear Safety Commission (CNSC)/U. of Toronto: ASR-effects on in-plane shear resistance of RC walls. The experimental program is complete and results are expected to be made public by the end of August following SMiRT 23.

2. NEXTera Energy (Seabrook NPP)/University of Texas at Austin:

- shear resistance (3-point bending test) of ASR-affected beam without shear reinforcement, and

- resistance of rebar anchorage/lap splice length embedded in beams (4-point bending test)

The beam geometries are similar to the TX DOT program previously mentioned although the vertical shear reinforcements have been removed to model wall found in nuclear structures. Results are proprietary to NEXTera Energy.

3. NRC/National Institute of Standards and Technologies (NIST) research program on ASR (initiated last year): Development of ASR damage development in partly confined beam, i.e., low/medium/high reinforcement.

4. Oak Ridge national Laboratory (ORNL)/UTK: Development of ASR damage development and outof-plane shear resistance in confined walls with no transverse reinforcement.

5. Institut de Radioprotection et de Sûreté Nucléaire (IRSN)/Ecole Normale Supérieure de Cachan (ENS): more details are expected to be provided by G. Nahas.

For the purpose of the modeling benchmark on structural members subjected to ASR, at this point, only past results (LCPC and TX DOT) are publicly available. ORNL is currently extracting the data from the TX DOT (bridge girders) report to evaluate how they can be used in the benchmark. A similar work will be performed after the release of the $\mathrm{U}$. of Toronto testing results. 